\title{
Follow-up of past participants of the Canadian Association of Gastroenterology Scholars' Program (2001 to 2005) - Where are they now?
}

\author{
Jose Nazareno MD FRCPC ${ }^{1}$, Clarence Wong MD FRCPC ${ }^{2,3}$, Jamie Gregor MD FRCPC 1,3 \\ ${ }^{1}$ Department of Medicine (Gastroenterology), University of Western Ontario, London Health Sciences \\ Centre, London, Ontario; ${ }^{2}$ Department of Medicine (Gastroenterology), University of Alberta, \\ Edmonton, Alberta; ${ }^{3} \mathrm{Co}$-Chairs, CAG Scholars' Program
}

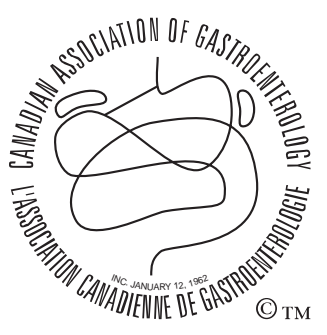

En français voir page 399
$T_{\mathrm{s}}^{\mathrm{h}} \mathrm{c}$ Canadian Association of Gastroenterology (CAG) Scholars' Program, previously called the Bright Lights Course, is designed primarily for senior medical students, and first- and second-year internal medicine and pediatric residents. It was started in 2001 to encourage trainees to consider a subspecialty career in gastroenterology. Each university is asked to nominate students or residents to attend. The program is limited to a maximum of 32 candidates, one to three of whom are taken from each medical school across Canada.

The two-day program, which is held before the Canadian Digestive Diseases Week conference, allows students the chance to work with and learn from an internationally recognized academic and clinical faculty who are respected leaders and role models in the field. Participants are provided with a view of the various careers that are possible in gastroenterology including basic science research, clinical research, medical education and community gastroenterology. The program also reviews ethical challenges, advances in gastroenterology, what it is like to be a gastroenterology fellow and emphasizes evidence-based gastroenterology. Participants have the opportunity to interact in small groups and to test their skills with an endoscopy challenge.

Initial informal feedback has been positive (1) and suggests that the program has helped to entice residents to pursue gastroenterology. To more formally assess the success of the program, we conducted a survey of the past participants of the CAG Scholars' Program. A list of all past participants from 2001 to 2005 was compiled. Contact information was updated through the CAG, the Canadian Medical Directory and a Web-based search. Over a one-month period, each past participant was contacted through e-mail and telephone (a maximum of two e-mails and telephone calls) at their last known e-mail address and telephone number.

In total, there have been 150 participants (56\% male and $44 \%$ female) in the CAG Scholars' Program (Table 1). At the time of participation, 22\% were medical students and 78\% were residents. Nineteen per cent were unable to be reached or did not respond to the messages. The current status is known in $81 \%(n=122)$ of the past participants.

Of those whose status is known, $70 \%$ are currently pursuing or planning to pursue gastroenterology, 26\% are not pursuing or not planning to pursue gastroenterology, and $4 \%$ are still undecided. Of the 70\% pursuing gastroenterology, 20\% are currently gastroenterology consultants, $43 \%$ are gastroenterology fellows, and $7 \%$ are medical students or residents planning on applying to gastroenterology (Table 1). Of the $26 \%$ not pursuing gastroenterology, $24 \%$ are currently residents or consultants in a different specialty and $2 \%$ are medical students or residents not planning on applying to gastroenterology. The most common alternate specialty among those who are not pursuing gastroenterology include cardiology (2), anesthesia (3), medical oncology (4) and general internal medicine (4).

To help assess the influence of the CAG Scholars' Program, the survey asked the past participants whether they were planning on pursuing gastroenterology before and after the course (Figure 1). Before the course, 60\% intended to pursue gastroenterology, $5 \%$ did not intend to pursue gastroenterology and $35 \%$ were undecided. After the course, $70 \%$ intended to pursue gastroenterology, $26 \%$ did not intend to pursue gastroenterology and $4 \%$ were undecided $(\mathrm{P}<0.001)$.

Finally, to help assess how the CAG Scholars' Program factored into the trainees career decision-making process, the past participants were asked how important the course was in their decision-making process when choosing a specialty or subspecialty. On a scale of 1 to 5 , an answer of 1 indicated that it was not important at all and an answer of 5 indicated that it was extremely important (Figure 2). The mean and median responses were 2.93 and 3 , respectively.

In 2004, the CAG developed a five-year strategic plan for July 2004 to June 2009 (5). One of its principal initiatives was to "emphasize the development of the next generation of gastroenterology clinical practitioners, researchers, educators, and leaders" and to "attract, train, and retain the best and the brightest to gastroenterology". The CAG Scholars' Program is considered one of the means to achieve this end. While informal feedback has been positive (1), this is the first time it has been formally assessed. Even accounting for those who either did not reply and those lost to follow-up, the majority of past participants did end up training in gastroenterology.

Most of the participants had an interest in gastroenterology before attending the course. The retention rate among this group was quite high. Of those who stated that they were

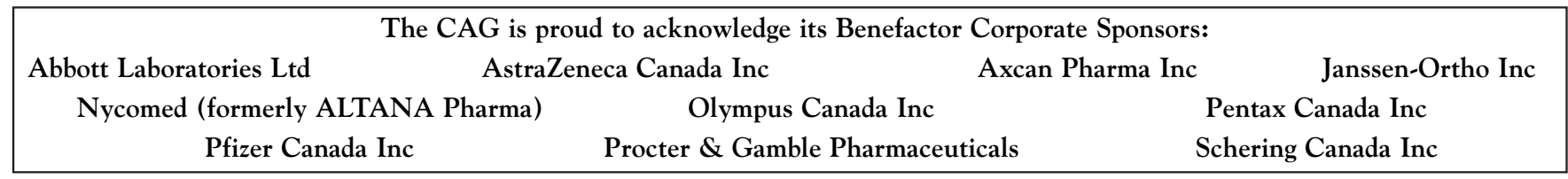


Table 1

Demographics of past participants of the Canadian Association of Gastroenterology Scholars' Program (2001 to 2005) $(n=150)$

\begin{tabular}{lc}
\hline Characteristic & Results \\
\hline Sex, \% & 56 \\
Male & 44 \\
Female & \\
Level at participation, \% & 22 \\
Medical student & 78 \\
Resident & \\
Current status, $\mathrm{n}$ & \\
Gastroenterologist (n=85) & 24 \\
Consultant & 52 \\
Fellow & 9 \\
Resident planning on gastroenterology & \\
Not a gastroenterologist (n=32) & 28 \\
Consultant or resident already in a different specialty & 30 \\
Resident not planning on gastroenterology & 2 \\
Undecided & 5 \\
No response or unable to reach & \\
\hline
\end{tabular}

interested in gastroenterology before attending the course, only $6 \%$ did not pursue gastroenterology or stated that they were not interested in pursuing gastroenterology after the course. In addition, among those who were initially undecided on a specialty before the course, another 39\% ended up pursuing gastroenterology after the course. It would seem that in addition to confirming and reinforcing the desire of those participants who were already intending to pursue gastroenterology, the program also converted some of those who were initially undecided.

The number of residents $(78 \%)$ invited to the program greatly outnumbered the number of medical students $(22 \%)$. Although this balance seems disproportionate, the program has been stated to be primarily for first- and second-year residents (4). In fact, by selecting more residents than medical students, the yield of attracting future gastroenterologists may be higher. Among medical students invited to the program, only $36 \%$ ended up pursuing or are planning to pursue gastroenterology. By comparison, $82 \%$ of residents invited to the course ended up pursuing or are planning to pursue gastroenterology $(\mathrm{P}<0.001)$. This observation is supported by a recent survey of current gastroenterologists (3) in which $63 \%$ stated that it was during residency that they made the decision to pursue gastroenterology. By comparison, only $15.8 \%$ decided on gastroenterology during their clerkship years.

Another observation from the survey was that the number of women being attracted to gastroenterology seemed to be increasing. In 2004, it was reported that only $15.6 \%$ of current practicing gastroenterologists were women (3). On the other hand, there was an almost equal participation rate between women (46\%) and men (54\%) in the CAG Scholars' Program. This figure is close to the average number of females entering medicine, which is $56.9 \%$ (3).

Approximately 10 years ago, it was reported that Canada had 1.1 gastroenterologists per 100,000 people (6). In comparison, the United Kingdom had 1.7 gastroenterologists

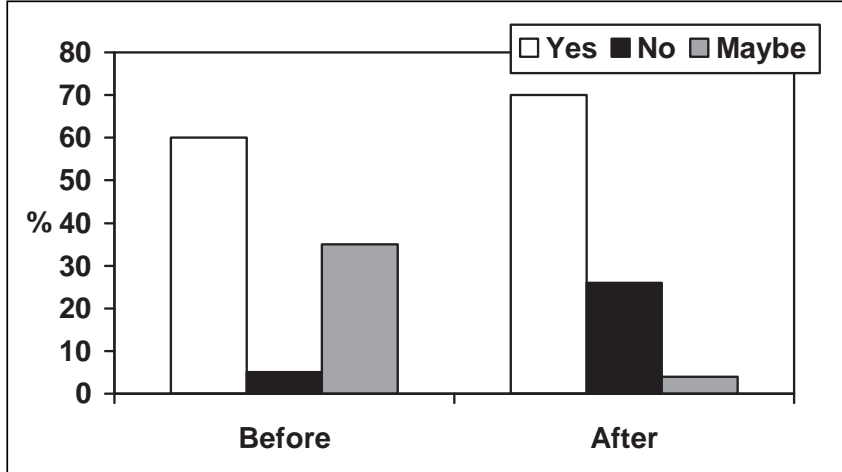

Figure 1) "Were you planning to pursue gastroenterology?" Responses of past participants before and after the Canadian Association of Gastroenterology Scholars' Program

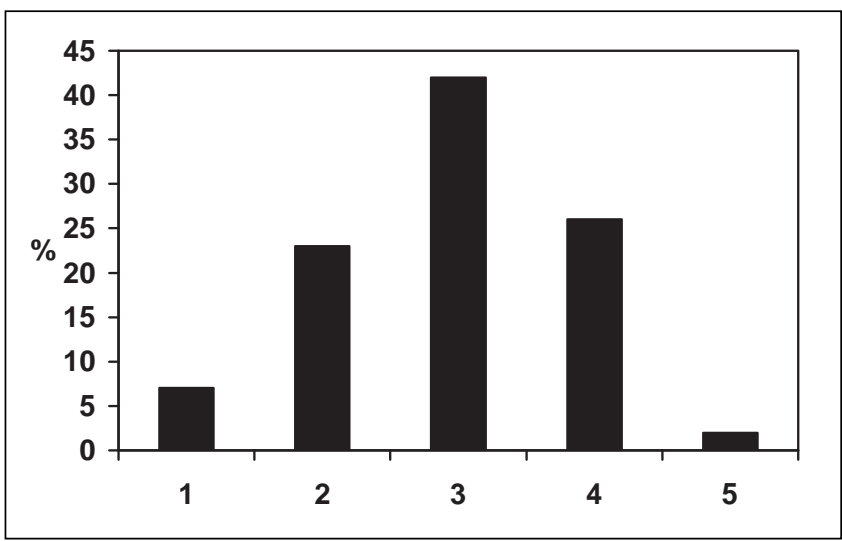

Figure 2) "How important was the Canadian Association of Gastroenterology Scholars' Program in your decision-making process when choosing a specialty?" 1 = Not important, $5=$ Extremely important

per 100,000 people and the United States had 3.1 gastroenterologists per 100,000 people. More recent data presented by Dr Paul Moayyedi (McMaster University, Hamilton, Ontario) at the 2006 Canadian Digestive Diseases Week conference (2) showed that Canada had 1.8 gastroenterologists per 100,000 people, which still ranks among the lowest in the western world. In fact, it was estimated that with the current number of trainees the number of gastroenterologists will actually decline by approximately $10 \%$ in the next five to 10 years. Through initiatives such as the CAG Scholars' Program, we can hopefully reinforce the interests of trainees who are interested in gastroenterology, convert some of those that are undecided and continue to attract the best and the brightest to our field.

\section{REFERENCES}

1. Bridges RJ. The Canadian Association of Gastroenterology education committee report. Can J Gastroenterol 2004;18:631-3.

2. Paterson WG. Message from the CAG President. Can J Gastroenterol 2006;20:437.

3. The College of Family Physicians of Canada. National Physician Survey (NPS) 2004: Specialist physician results. <http://www.cfpc.ca/ nps/English/Spec_Gastro.asp> (Version current at April 9, 2007).

4. Gregor J. Reflections on the third annual CAG Scholars' Program. Can J Gastroenterol 2003;17:455.

5. Sherman PM, Fedorak RN, Leddin D, Wallace JL. Canadian Association of Gastroenterology 2004 strategic plan. Can J Gastroenterol 2004;18:125-6.

6. Meyer GS, Jacoby I, Krakauer H, Powell DW, Aurand J, McCardle P. Gastroenterology workforce modeling. JAMA 1996;276:689-94. 


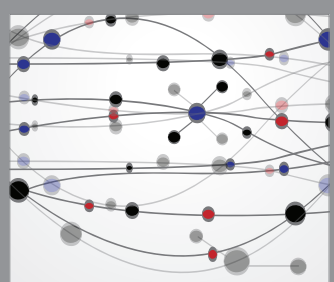

The Scientific World Journal
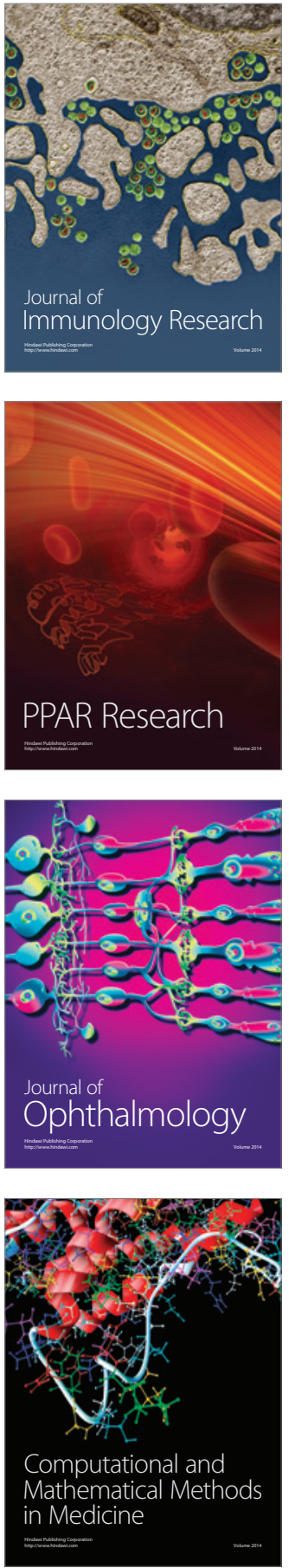

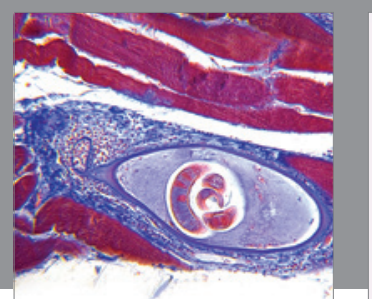

Gastroenterology Research and Practice

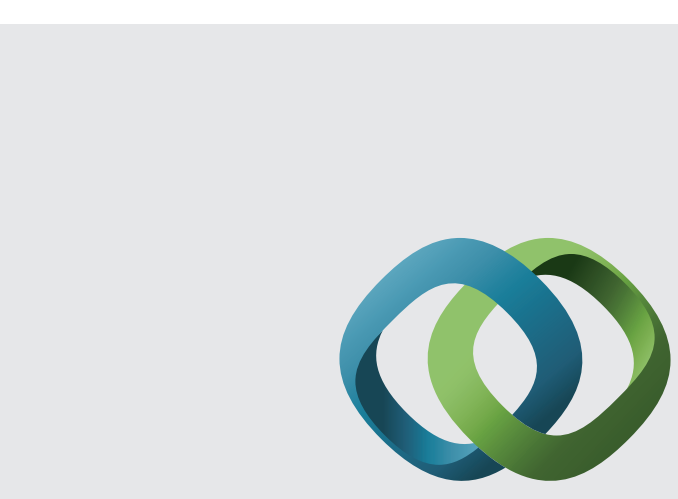

\section{Hindawi}

Submit your manuscripts at

http://www.hindawi.com
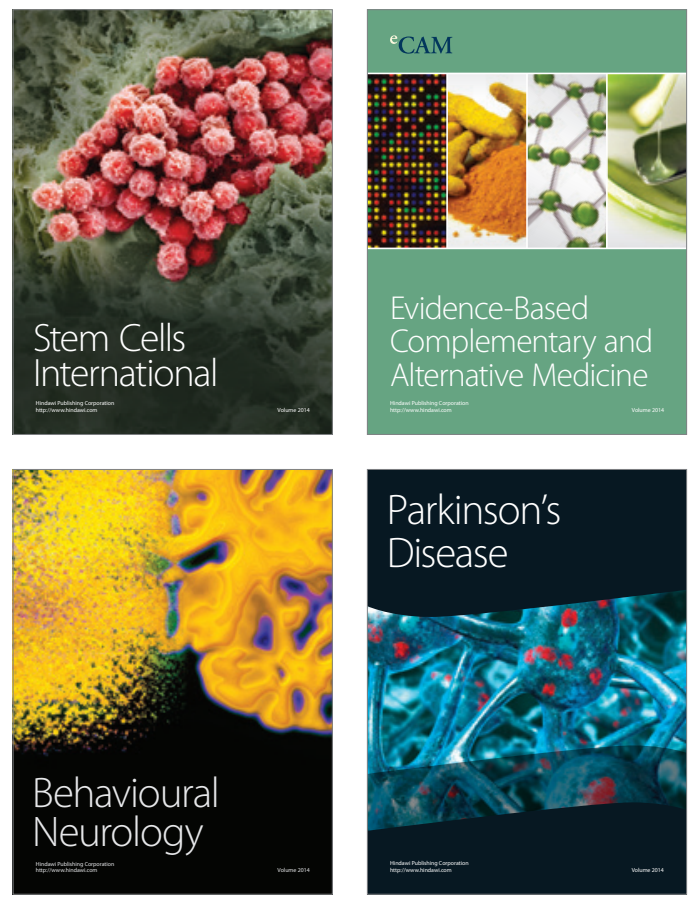
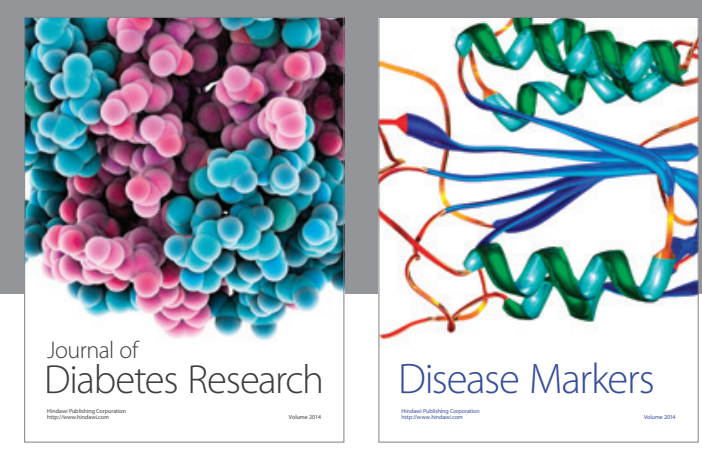

Disease Markers
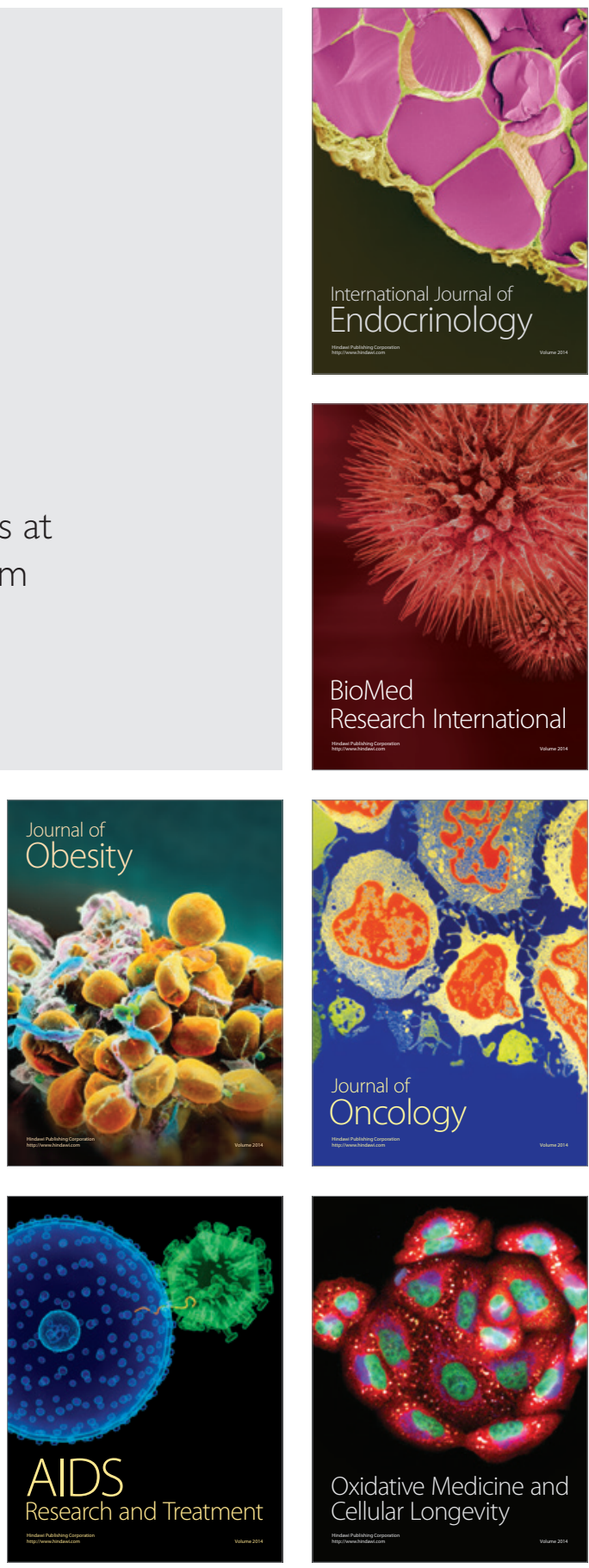